\title{
Albumin Clearance
}

National Cancer Institute

\section{Source}

National Cancer Institute. Albumin Clearance. NCI Thesaurus. Code C147293.

The determination of the clearance of endogenous albumin, used for evaluating the glomerular filtration rate. 